\title{
Brief Analysis on Human Resources Management in Modern Private Enterprises
}

\author{
Pingping Zhao \\ College of Education Science, Qufu Normal University \\ Qufu 273165, China \\ E-mail: zhaoping613@163.com \\ Yanran Yuan \\ Department of Children Rehabilitation, Jining First People's Hospital \\ Jining 272100, China \\ Yongxiang Guo \\ College of Education Science, Qufu Normal University \\ Qufu 273165, China
}

\begin{abstract}
Currently in China, private enterprises have become the backbone of promoting Chinese economic development and social progress. However, many private enterprises to some extent experience difficulties in human resources management in their development because of some intrinsic and historical reasons, which slows down the speed of their sustainable development. On the basis of clarifying the concept and function of human resources, human resources management and private enterprises, by analyzing the present condition of private enterprises' human resources management, this thesis illustrates how to improve the mechanism of using, keeping and training the employees of private enterprises, and proposes the measures of personalized human resources management in private enterprises.
\end{abstract}

Keywords: Human resources management, Private enterprises, Predicaments, Countermeasures

\section{Introduction}

Along with economic development and changes in people's concept, all trades and professions in our country emerge a number of private enterprises and private entrepreneurs that promote the economic development a lot. Among these enterprises, some have grown up successfully, but many have disappeared in the growing process. On the whole, the developing condition of Chinese private enterprises is much more difficult than state-owned enterprises in many aspects, so a lot of private enterprises present a phenomenon of "lasting briefly, and growing with difficulty".

Why are small and medium private enterprises which are very successful at an early stage depressed or collapsed eventually? There are many reasons. A key one is the problem of enterprises' human resources management.

"Human resources" was first brought into China by foreign enterprises. Nowadays, many enterprises in our country have changed "personnel department" into "human resources department". However, in the face of the increasingly fierce market competition, it is not enough to change the name only. We should understand the meaning of "human resources" deeply, and do a good job on human resources management. Only in this way can the private enterprises continue to tap their potential and stand firmly in the trends of market economy.

\section{Meaning of private enterprises, human resources and human resources management}

Private economy is the term emerged in China in the late 1980s and early 1990s. At present, the economic entities that invested by non-state economy or managed by the private enterprises or operator who do not represent the state asset may be called privately operated economy. The enterprises that based on private capital can be called private enterprises. Now in China, with the economic development and the market opening, more 
and more private enterprises appear. They play an important role in guaranteeing the moderate increase of Chinese economy, alleviating employment pressure, facilitating the populace to live, promoting technological innovation, advancing economic development, maintaining social stability and so on.

Human resources refer to the workers' ability that promotes the entire economic and social development, including the ability of the intellectual work and that of the physical work (Cao Xianjin \& Yu Kaichao, 2007). Broadly speaking, people with normal intelligence are human resources. But human resources here mainly refer to the sum of people capable of work both inside and outside the enterprises organization.

Human resources management refers to the effective development, reasonable utilization and scientific management of human resources. It uses modern scientific methods to manage people's ideas and behaviors effectively and gives full play to people's initiative in order to achieve business goals. The functions of human resources management are planning, selection, evaluation, motivation, development and deployment (Cao Xianjin \& Yu Kaichao, 2007).

\section{Analysis on the human resources management predicaments of the private enterprises}

With the structural reform deepened, private enterprises cannot rely on mechanism to gain mass market opportunities in the circumstances that the intrinsic conditions have been changed in the macro economic environment and the micro economic subjects. On the contrary, private enterprises' original management deficiencies are exposed day by day and become restricts of their growth. The management problems are mainly reflected in the following aspects: the contradiction between enterprises' size expansion and management capacity's insufficiencies; the serious "insider" control phenomenon caused by the unclear property right; the decline of the staff cohesion; the contradiction between arbitrary policy-making and the long-term need for rational decision pursued by enterprises; the contradiction between emotional ties and systematic standard management. These contradictions highlight the focus on enterprises' internal human resources management.

\subsection{The weakened human resources management ideas}

Most of the policy-makers in private enterprises do not have a deep awareness and understanding of human resources management. At present, as for the private enterprises in our country, their understanding of human resources management still remains on the level of general affairs management. Their duties are to organize, coordinate, control and supervise the relationship with affairs. They aim at matching people and things, which takes things as the center and asks people to adapt to things. In other words, they lay more emphasis on the uses of the personnel than training them.

\subsection{The lack of scientific human resources strategy}

Human resources strategy is the significant part of enterprises strategies. Human resources are the important strategic resources of the organization, which to some extent directly determines the organization strategy's success or failure. In recent years, private enterprises develop rapidly, so the human resources are in short supply, especially the insufficiency of the intermediate and senior managers and technical talented people makes the private enterprises development lack of stamina.

\section{3 "Family Type" management-inbreeding, chaotic management}

According to the investigation, about $90 \%$ financial management of private enterprises is controlled in family members and about $40 \%$ intermediate and senior managers are family's friends or its members (Luo Mei,2004). Many private management systems are not perfect. In the start-up period, they are often combined by families and friends. When they develop to a certain scale, they are still in the "inbreeding" stereotypes. The personnel management still stays at arbitrary "domestic workshop" policy-making stage, which impacts on the talented people's work enthusiasm, and thereby impedes the enterprises' development.

\subsection{The rapid staff turnover and the difficult trained personnel stability}

Under the modern market economy, the flow of trained personnel is getting quicker and quicker and the system is more and more flexible. A lot of private enterprise bosses think that as long as they have money, it is not a question to find workers. However, the backbone workers depart with not only technology, market and other resources, but leaves behind the insecurity and uncertainty which is more terrible to shake the morale and cause the "job-hop". Besides, it may lead to the loss of senior managers and influence the morale and organization atmosphere (Li Rong \& Xu Jie, 2004).

\subsection{Low quality of the administrators}

In the era of knowledge economy, the staff's quality is requested higher and higher. The current statuses of private enterprises' administrators are: (1) education is not high. The personnel of group companies and 
high-tech industry have high academic qualifications, but the others have low ones;(2) modern enterprises management's basic knowledge is deficient, especially the management ways that still in experience management stage; and(3) the professional structure is single and multi-skill managerial personnel are few, especially in some high-tech private enterprises, most of their management personnel are technical staff that lacks necessary management knowledge (Chu Xiaoping, 2002).

\subsection{False attitude towards training and development of private enterprises}

On the one hand, the attitude of the enterprises' decision-makers towards training is not correct. To the low level superintendents, the decision-makers worry that the enterprises have no strict restraint mechanism to them. If they leave after training, the enterprises will lose personnel and money (Liu Sicong, 2003). On the other hand, the private enterprises have no systematic nature and long residual action on the training development and pay a little for it. So the improvement to the enterprises cultural construction and personnel quality become empty talk and the management personnel team construction cannot make a substantial progress.

\subsection{The lack of long-term effective salary and incentive mechanism}

Currently, most human resources management of private enterprises are still in the traditional human resources management stage, which overemphasizes the management system and procedure formulation and neglects to set up effective incentive mechanism (Liu Zhuomin, 2002). A number of private enterprises realize the importance of talents and use high salaries or other material incentives to attract talents, which do not have too many deficiencies at the beginning stage of the enterprises. With the development of the enterprises and the complex of the personnel structure, salaries for the core staff are not only a means of livelihood, but also the need of self-satisfaction and self-esteem. It is believed that the enterprises will lack cohesion and the personnel will lack a sense of belonging if the employees are motivated only by increasing the reward without non-material incentives (such as the ideal incentive, goal incentive, model incentive, training incentive, self-realization incentive and so on) (Chen Ruoyu, 2002).

\subsection{The indifference on personnel regulations and policies}

In China's private enterprises, some managers only understand the importance of technology, products and markets, but pay less attention on the importance of human resources management. Therefore, they select the human resources managers at a random. These human resources managers usually play multiple roles. They do not understand personnel policies and have no specialized personnel management knowledge and experience, so they do not consider the personnel regulations but only rely on their bosses' ideas. What's worse, some private enterprises often change their workers in a large scale for a partial small profit, which causes the staff turnover increase quickly and limit the business development.

\section{The countermeasures of the human resources development and management in private enterprises}

For private enterprises, they should, on the basis of establishing and perfecting modern enterprises' system, form the concept of modern human resources management, should give insight to the staff's value from the angle of resources, and should realize the transformation from the traditional personnel management to the modern human resources management, by applying the new human resources management theory and method.

\subsection{Completing human resources' developing program and regulating the management mode}

Human resources' developing program mainly concerns: the predication of the future manpower needed by an enterprise, the predication of internal manpower supply and external manpower supply. In the human resources program, the development of an enterprise and the development of staff depend on each other and promote each other. An excellent human resources program is the one that can make the enterprises and their staff develop together. By making a human resources program, we can change the enterprise's goal and strategy into the demand of manpower to attain the balance between quality and quantity, between long-term and short-term manpower's supply and demand. Therefore we can realize the scientific and reasonable exploitation of human resources.

\subsection{Stabilizing enterprises' employing contract system}

Recently, the number of the part-time workers and contract workers employed by the enterprises is increasing quickly. Comparing to the traditional employing contract system, the new employing contract system should consider the need of enterprises and their staff, rather than only to attain the short-term requirement of reducing the cost of the enterprises. In modern times, staff's contract should include the enterprises' explanation on various aspects: the understanding of the contracts, the relation between labor and capital, and the posts description, enterprises' culture, and so on (Wang Yu, 2001). But in fact, there are still a lot of private enterprises 
or joint ventures who don't sign the trial or standard contracts after establishing the oral contracts with the applicants. Therefore appears the case that one dare not go to work even if he/she gets a job. So if the private enterprises can establish reasonable and effective employing contract systems, they will do much good to the employment and use of workers.

\subsection{Using the modern examining system and perfecting the talented personnel encouraging mechanism}

Examining lies in the core of the modern human resources management. In the recent phase, we are using the extensive ways in terms of examining: more quality examining but less quantity examining. Therefore, as for the examining ways, we can divide the content into four elements: moral, ability, diligence, achievements according to the way of decomposing elements. The examining can be classified into two parts: the examining of moral and ability, the examining of diligence and achievements. On the basis of the examination, the proper income distribution and encouragement mechanism, which is fit to the talented personnel's contribution, should be set up and completed as soon as possible. The high-level talented personnel should be given high salary, the first class fruits and achievements should be given first-class rewards, and the talented personnel with prominent contribution should be given big rewards (Chen Ruoyu, 2002)

\subsection{Establishing the mechanism against talented personnel's loss, and perfecting the internal training system of enterprises}

The loss of talented personnel will lead to the loss of the capital of talented personnel. If the enterprises want to keep the talented personnel, they should improve the staff's knowledge and skills. The administrators of the enterprises should make corresponding arrangements according to the workers' skills and change their tasks according to their capabilities (Liu Zhuomin, 2002).

Internal training is an important way to meet the demands of human resources in enterprises (Yan Hongyan, 2007), especially for the private enterprises. The stabilization of the workers in an enterprise is not only related to the rewards and working environments, but also to the chances of training and to the help to their self-improvement and later developments. When accepting the internal training, the workers should not only learn the practical skills but also learn the "soft knowledge" and "soft skill" such as the knowledge of the administration system and the coordination between the leadership and the staff, and so on. Thus, it is beneficial to the improvement of the stability of the employment, and to the formation and accumulation of special manpower capital.

\subsection{Broadening the selective range of human resources}

As for the selection and employment of human resources, the way that makes use of personnel according to the traditional seniority and that appoints people by favoritism should be changed immediately, to broaden the selective range of talented personnel, to increase the attraction to the external personnel, and to strengthen the competitive mechanism, and to create the opportunity for the talented personnel to become prominent. On the one hand, through additional studies and consigning the training of personnel to certain colleges, enterprises can cooperate with the colleges to cultivate the talented personnel who can be exploited and kept working by them; on the other hand, enterprises can employ the graduates from the colleges or universities, who can be placed on the front line of production operation. In addition, enterprises can employ the professionals in colleges and universities as counselors or part-timers.

\subsection{Perfect the establishment of institution, and allocate enough and high qualified human resources} administrators

At the new people-oriented age of administration, it is unimaginable for the lack of true human resources management branches in private enterprises. Private enterprises must perfect the establishment of human resources management institution, and adjust the organizational structure. Private enterprises should establish the special human resources management branches, which can implement the management duty of human resources to make the human resources management and policy deciding scientific and standard. From the angle of the current situation, private enterprises can attract some external human resources management professionals to join in them, and popularize the concept and knowledge of human resources management among the enterprise proprietors, and cultivate professional management talented personnel of human resources.

\subsection{Building favorable atmosphere of corporate culture}

A great deal of researches and facts indicate that successful enterprises always own strong and forceful corporate culture. Corporate culture is regarded as the key element leading to an enterprise's successful operation. Establishing and forming excellent corporate culture, which has an enormous influence for the long term development of an enterprise, is an important way for effective administration and improved business 
performance (Zhao Hongxia, 2006). The excellent corporate culture must be that which can guarantee the staff more studying opportunities and skills development. A proper cultural atmosphere of its own once forming in an enterprise, it will enable its staff to accept it and blend into it and to form a sense of belonging and identity.

In sum, Chinese private enterprises should, starting from its own situation, form a particular human resources management mode by widely collecting others' advantage to fuse and refine. As for the human resources deployment, it should focus on the cultivation and regard the introduction as complementary; as for human resources management, it should show institutionalization and humanity; as for human resources encouragement, it should show the combination of material guarantee and spiritual encouragement(Ma Chao \& Ling Wenquan, 2004).Human resources management, related to the enterprise's strategic management and corporate culture and so on, is a vital task in an enterprise, which not only determines the present but also the future of an enterprise. It needs any boss of the enterprise to think about the human resources management problem in his enterprise according to the enterprise' $s$ rules in order to improve his level of understanding the human resources and to promote his enterprise's favorable development.

\section{References}

Cao, Xianjin \& Yu, Kaichao. (2007). Human resources management problems and countermeasures in private enterprises. National Business (Economic Theory Studies), 3.

Chen, Ruoyu. (2002). Several thinking about the effectiveness of encouragement. Academic Journal of Huaiyin Institute of Technology, 2.

Chu, Xiaoping. (2002). Family firms study: a subject being of modern sense. Social Sciences in China, 5.

Li, Rong \& Xu, Jie. (2004). On the thinking of human resources management in private enterprises. Academic Journal of Party School of CCP Nanchang Committee.

Liu, Sicong. (2003). The analysis of the qualities of successful private enterprisers. Inner Mongolia Social Sciences, 4.

Liu, Zhuomin. (2002). The influence and control of the loss of talents. Manpower Development, 5.

Luo, Mei. (2004). The limitation and breakthrough of human resources management in private enterprises. Academic Journal of Sichuan Administration College, 5.

Ma, Chao \& Ling, Wenquan. (2004). The new angle of human resources management: Organizing Politics. Manpower Resources Development in China, 6.

Wang, Yu. (2001). The new way of human resources management. Academic Journal of Shanxi Institute of Technology, 3 .

Yan, Hongyan. (2007). To take people as the foremost and promote the development of the enterprises. Academic Journal of Liaoning Administration College, 2.

Zhao, Hongxia. (2006). From culture to cooperate culture. Academic Journal of Trade Union Management College in Shandong Province, 5. 